\title{
PRODUÇÃO DE MUDAS DE CARAMBOLEIRAS 'B-10’ E 'GOLDEN STAR': I - PARÂMETROS BIOLÓGICOS'
}

\author{
DANILO EDUARDO ROZANE ${ }^{2}$, RENATO DE MELLO PRADO ${ }^{3}$, WILLIAM NATALE ${ }^{3}$, \\ LILIANE MARIA ROMUALDO ${ }^{4}$, HENRIQUE ANTUNES DE SOUZA 5 , \\ SILVIA HELENA MODENESE GORLA DA SILVA ${ }^{2}$
}

RESUMO - O Brasil é um dos maiores produtores de carambola do mundo, entretanto há poucas informações científicas, especialmente estudos de nutrição mineral com mudas dessa frutífera. Objetivando contribuir com o conhecimento desse importante aspecto, desenvolveu-se estudo que permitisse avaliar o crescimento e o acúmulo de nutrientes em mudas de caramboleiras, cultivadas em solução nutritiva. $O$ experimento foi realizado em parcelas subdivididas, sendo utilizadas como parcela as duas cultivares de caramboleira ('B-10' e 'Golden Star') e, como subparcelas, as cinco épocas de coleta de plantas, realizadas aos 208; 233; 258; 283 e 308 dias após o transplantio para a solução nutritiva. O delineamento foi inteiramente casualizado, com três repetições. As mudas foram cultivadas em vasos $(8 \mathrm{~L})$ com solução nutritiva $(\mathrm{pH}=5,5 \pm 0,5)$, com aeração. O experimento iniciou-se em 24-08-2005. Nos diferentes órgãos das mudas (folhas, caule e raízes), avaliaram-se o crescimento e o acúmulo de nutrientes, e os índices nutricionais. Não houve diferenças no crescimento e, em geral, no acúmulo da massa da matéria seca entre as duas cultivares. Houve acúmulo linear da massa da matéria seca das mudas de caramboleira com o tempo de cultivo, sendo maior nas folhas $>$ caule $>$ raízes. O período de maior acúmulo da massa de matéria seca e da taxa de crescimento relativo na planta inteira esteve compreendido entre 208 - 233 e 233 - 258 dias após o transplantio para a 'B-10' e a 'Golden Star', respectivamente.

Termos para indexação: Averrhoa carambola, exigência nutricional, solução nutritiva, marcha de absorção.

\section{PRODUCTION OF SEEDLINGS OF STAR FRUIT 'B-10' AND 'GOLDEN STAR': I BIOLOGICAL PARAMETERS}

\begin{abstract}
Brazil is one of the greatest producer of star fruit in the world, however, there are few scientific information, especially studies of mineral nutrition with seedlings of this fruitful. In order to contribute with the knowledge of this important aspect, it was developed a study that allowed evaluating the growth and the accumulation of nutrients in seedlings of star fruits trees, cultivated in nutritional solution. The experiment was realize in split plot, with two cultivars ('B-10' and 'Golden Star') and as subplots, five collecting periods of plants, realized in 208, 233, 258, 283 and 308 days after the transplantation to nutritional solution, with 3 repetitions. The seedlings had been cultivated in pots $(8 \mathrm{~L})$ with nutritional solution $(\mathrm{pH}=5.5 \pm 0.5)$, with aeration. The experiment started on 08-24-2005. In the different parts of the seedlings (leaves, stem and roots), it was evaluated the growth and the accumulation of nutrients and nutritional ratios. It did not have differences in the growth and, in general, in the accumulation of the dry matter between the two cultivars. There was linear accumulation of the dry matter of the seedlings of star fruit trees with the cultivation period, it was bigger in leaves $>$ stem $>$ roots. The period of greater accumulation of dry matter and the tax of relative growth in the entire plant was between $208-233$ and $233-258$ days after the transplantation for 'B-10' and 'Golden Star' respectively.
\end{abstract}

Index terms: Averrhoa carambola L., nutritional requeriments, nutrient solution, uptake rate.

\footnotetext{
'(Trabalho 017-11). Recebido em: 04-01-2011. Aceito para publicação em: 31-05-2011.Parte da Tese de Doutorado do primeiro autor. 2Prof. Assistente Doutor, Universidade Estadual Paulista "Julio de Mesquita Filho" Unesp-Câmpus Experimental de Registro, Rua Nelson Brihi Badur, n 430, Vila Tupy - 11900-000 Registro-SP. E-mail: danilorozane@registro.unesp.br; silvia@registro.unesp.br ${ }^{3}$ Professor Adjunto, Dept ${ }^{\circ}$. de Solos e Adubos, FCAV/Unesp. Bolsista PQ do CNPq. E-mail: rmprado@fcav.unesp.br; natale@fcav.unesp.br ${ }^{4}$ Doutoranda, USP/FZEA. E-mail: lilianeromualdo@yahoo.com.br

${ }^{5}$ Pesquisador Embrapa Caprinos e Ovinos. E-mail: henrique@cnpc.embrapa.br
} 


\section{INTRODUÇÃO}

A caramboleira (Averrhoa carambola L.) pertence à família Oxalidaceae, originária da Ásia, sendo típica das regiões tropicais. Apesar de ser uma frutífera exótica, o Brasil é um dos maiores produtores mundiais, sendo cultivada em quase todo o País, com exceção das zonas mais frias (OLIVEIRA et al., 1989). É tida como frutífera de alto potencial de exploração, devido ao rápido desenvolvimento, à alta produtividade, à possibilidade de contornar fatores limitantes ao cultivo, à baixa exigência quanto aos tratos culturais e ao fato de produzir frutos com aparência, sabor, aroma e propriedades nutricionais únicas (GALAN SAUCO et al., 1993). Além destes aspectos, os frutos da caramboleira destacam-se pela sua beleza exótica e única na natureza, o que os torna bastante atrativos ao consumidor.

A produção de mudas de caramboleira com adequado estado nutricional é um dos fatores primordiais que determinam o sucesso na implantação do pomar, podendo afetar a precocidade da produção, refletindo no retorno econômico do capital investido pelo empresário agrícola.

Desse modo, para a nutrição adequada das plantas, além da quantidade e da relação entre nutrientes, é preciso conhecer a dinâmica de acúmulo de elementos na matéria seca ao longo do tempo de cultivo, pois o desbalanceamento nutricional pode acarretar prejuízos às mudas, alterando seu crescimento e início reprodutivo. Contudo, essa informação indica apenas o total acumulado, e não o que deve ser aplicado, pois deve considerar-se a eficiência de aproveitamento de cada nutriente em função das condições de cultivo.

Existem alguns estudos relacionados à nutrição e adubação da caramboleira, entretanto não foram encontradas informações científicas nas literaturas nacional e internacional sobre o crescimento e o acúmulo de nutrientes em mudas de caramboleira, sobretudo para as cultivares 'B-10' e 'Golden Star', que possibilitem sustentar o entendimento do crescimento, da demanda nutricional e programas de adubação. Isso suscita preocupação, devido ao manejo empírico da aplicação de fertilizantes realizada pelos produtores de mudas.

Assim, objetivou-se determinar o crescimento e o acúmulo de nutrientes em mudas de caramboleira 'B-10' e 'Golden Star'.

\section{MATERIAL E MÉTODOS}

O experimento foi realizado em casa de vegetação, na FCAV/UNESP, Câmpus de Jaboticabal - SP, com coordenadas $21^{\circ} 15^{\prime} 22^{\prime \prime}$ sul, $48^{\circ} 18^{\prime} 58^{\prime \prime}$ oeste e altitude de $615 \mathrm{~m}$, com hipobiotos (portaenxertos) provenientes da cultivar Malásia, enxertados com epibiotos (enxertos) de caramboleiras das cultivares B-10 e Golden Star.

Os hipobiotos utilizados no experimento foram provenientes de propagação sexuada (sementes), como indicado por Donadio et al. (2001). Para isto, foram selecionados frutos maduros, em um pomar de caramboleiras adultas 'Malásia', na Estação Experimental de Citricultura de Bebedouro - SP, dos quais se extraíram as sementes, que foram cultivadas individualmente em tubetes plásticos de $53 \mathrm{~cm}^{3}$ contendo casca de pínus e vermiculita até 120 dias após sua germinação. Após esse período, as raízes das plantas foram submetidas à lavagem, para a retirada de todo o substrato aderido ao sistema radicular, a fim de transplantá-las para o cultivo hidropônico.

Utilizou-se a solução nutritiva de Furlani et al. (1999), indicada por Rozane et al. (2007), como adequada para o cultivo de mudas de caramboleira. A adaptação dos hipobiotos ocorreu nos primeiros 15 dias após o transplantio (DAT), sendo os mesmos mantidos em solução nutritiva completa, diluída a $1 / 4$ da concentração preconizada, e após esse período, até o final do experimento, a solução foi completa, sem diluição.

Após 125 dias da realização do transplantio para a solução nutritiva, em 27-12-2005, os hipobiotos apresentavam-se aptos (diâmetro do caule $>6,0$ $\mathrm{mm}$ ) à enxertia, realizada pelo método da borbulhia, com os epibiotos da 'B-10' e da 'Golden Star', provenientes da coleção de cultivares da Estação Experimental de Citricultura de Bebedouro - SP.

Empregaram-se, para o cultivo das plantas, as mesmas técnicas e padrões utilizados na produção de mudas nos viveiros comerciais, como preconizado por Donadio et al. (2001), sendo necessária a poda da parte aérea do hipobioto a $0,40 \mathrm{~m}$ do colo da planta, no momento da enxertia. A retirada do fitilho plástico ocorreu 45 dias após a realização da enxertia, em 10-02-2006 e, decorridos mais 30 dias, em 12-032006, realizou-se nova poda do hipobioto a $0,015 \mathrm{~m}$ do enxerto, com posterior aplicação de pasta cúprica (0,9g/i.a. por litro de água de Oxicloreto de cobre) no local do corte.

$\mathrm{O}$ experimento foi realizado em parcelas subdivididas, sendo utilizadas como parcela as duas cultivares de caramboleira ('B-10' e 'Golden Star') e, como subparcela, as cinco épocas de coleta de 
plantas realizadas aos 208 (20-03-2006), 233 (1404-2006), 258 (09-05-2006), 283 (03-06-2006) e 308 (28-06-2006) DAT para a solução nutritiva. Adotou-se o delineamento inteiramente casualizado, com três repetições, sendo que cada repetição representou a média de quatro plantas, totalizando 24 mudas por coleta.

As plantas foram acondicionadas em vasos de polipropileno, com $8 \mathrm{~L}$ de capacidade e formato trapezoidal $(0,48 \mathrm{~m}$ de comprimento na parte superior, $0,44 \mathrm{~m}$ de comprimento na base inferior, $0,16 \mathrm{~m}$ de largura e $0,17 \mathrm{~m}$ de altura). Durante o período experimental, realizou-se o rodízio dos vasos na bancada.

Para o manejo da solução nutritiva, ao longo do período de estudo, o $\mathrm{pH}$ da solução foi monitorado diariamente, ajustando-se a 5,5 $\pm 0,5 \mathrm{com}$ solução $\mathrm{NaOH}$ ou $\mathrm{HCl} 0,1 \mathrm{M}$. Na mesma ocasião, foi monitorada a condutividade elétrica da solução nutritiva, com o auxílio de um condutivímetro portátil, mantendo-a com valor entre 2,0 e $2,4 \mathrm{dS} \mathrm{m}^{-1}$. A reposição da água evapotranspirada foi realizada com água destilada. A solução nutritiva dos vasos foi oxigenada constantemente, empregando-se um borbulhador acoplado a um compressor de ar, sendo as soluções renovadas a cada 25 dias, por ocasião da cada coleta das plantas.

Avaliaram-se, em todas as coletas, as seguintes variáveis biométricas: altura (do colo da planta até a extremidade da última folha expandida); diâmetro do caule (a 0,08 $\mathrm{m}$ do colo da planta, determinado com o auxílio de um paquímetro digital); e a área foliar (determinada com o auxílio de um aparelho integrador de áreas portátil, LI-COR ${ }^{\circledR}$ modelo LI-3100). Em seguida, as plantas foram divididas em raízes, caule e folhas, lavadas em água destilada e secas em estufa com circulação forçada de ar, à temperatura de $65^{\circ} \mathrm{C} \pm 0,5$, até atingir massa constante, sendo determinada a massa da matéria seca das diferentes partes.

Com base nos resultados, foram realizadas análises de variância (teste F) para as diversas características estudadas, e o estudo da regressão, para tempo de cultivo, com o auxílio do programa ESTAT (1992). Em todas as variáveis, empregou-se o modelo de regressão, que resultou em significância, pelo teste $\mathrm{F}$, e que melhor representou a característica estudada.

Para o modelo logístico, empregou-se a equação citada por Hoffmam e Vieira (1977), representada por:

$$
Y=\frac{a}{1+e^{-k(x-x c)}}
$$

em que, $a$ : é o máximo acumulado assintótico; $e$ : é o inverso do logaritmo neperiano; $k$ : é a taxa média de acúmulo; $x$ : dias após o transplantio, e $x c$ : é o tempo necessário para atingir $50 \%$ do acúmulo máximo assintótico.

Determinou-se, ainda, a Taxa de Crescimento Relativo (TCR), estimada pela fórmula proposta por Welbank (1962):

$$
T C R=\frac{(\ln M 2-\ln M 1)}{(t 2-t 1)}=m g \text { porg por dia }
$$

em que, TCR: é a Taxa de Crescimento Relativo; $M 1$ e $M 2$ e : são a massa da matéria seca do órgão ou da planta referente aos tempos $t 1$ e $t 2$, respectivamente.

\section{RESULTADOS E DISCUSSÃO}

As mudas de caramboleira, nas condições experimentais, apresentaram adequado crescimento, havendo efeito significativo do tempo de cultivo sobre todas as variáveis analisadas. Entre as cultivares, houve diferença significativa somente para a massa da matéria seca das raízes (Tabela 1).

Pelo estudo da regressão, a 'B-10' e a 'Golden Star', em função do tempo de cultivo, apresentaram ajuste linear, com exceção da massa da matéria seca das raízes da 'Golden Star', que apresentou ajuste logístico (Figuras 1 e 2). Esses resultados discordam daqueles apresentados por Freitas (2008) que, ao cultivar caramboleira 'Nota10', em condições semelhantes, observou ajustes de modelos matemáticos diferenciados para cada variável de crescimento.

O crescimento de uma planta envolve divisão e expansão celular (BROWN, 1984). O processo de diferenciação é frequentemente considerado como parte do crescimento, sendo que o desenvolvimento vegetal requer tanto crescimento como diferenciação (GARDNER et al., 1985). Desta maneira, como descrito por Salisbury e Ross (1985), as mudas de caramboleiras encontram-se no início de seu desenvolvimento, justificando o ajuste ao modelo linear. Oliveira (1996) enfatiza, também, o rápido crescimento apresentado por plantas jovens de caramboleira, sugerindo que esta espécie é grande incorporadora de $\mathrm{CO}_{2}$.

Nesta fase de desenvolvimento, não houve necessidade de adaptação das mudas, pois a primeira coleta foi realizada aos 208 dias de cultivo em solução hidropônica, o que não propiciou qualquer estresse às plantas, promovendo ganho contínuo da TCR nos órgãos e, consequentemente, na planta 
inteira, implicando o ajuste linear das equações de acúmulo da massa da matéria seca. A relação entre no ajuste das equações e o TCR da planta pode também ser observado no acúmulo da massa da matéria seca das raízes da cultivar 'Golden Star' que, por apresentar a menor TCR na última avaliação (Tabela 2), teve melhor ajuste ao modelo logístico (Figura 2c).

O acúmulo da massa da matéria seca das raízes, do caule e das folhas das cultivares de caramboleira (Tabela1) explica o incremento da altura, do diâmetro do caule e da área foliar das mudas (Figuras 1a,b e 2a,b).

A produção da massa da matéria seca da planta inteira, aos 308 dias de cultivo, foi de 57,11 e 58,76 g por planta, para a 'B-10' e 'Golden Star', respectivamente, e obedeceu à ordem: folhas $(50$ e $48 \%$ ) > caule $(35$ e $34 \%$ ) > raízes $(15$ e $18 \%$ ).

A maior contribuição das folhas no acúmulo da massa de matéria seca da planta inteira foi também relatada por Freitas (2008), trabalhando com caramboleira; por Barbosa et al. (2003), com gravioleira; por Franco et al. (2007) e Augostinho et al. (2008), com goiabeiras. Este fato ocorreu, provavelmente, devido aos maiores drenos de assimilados serem as folhas, resultando em maior acúmulo da massa de matéria seca, visto que as raízes e o caule não apresentaram alta capacidade mobilizadora de nutrientes. Nesta fase de desenvolvimento inicial da caramboleira, o maior acúmulo de biomassa nas folhas é justificado para incrementar a área foliar, cuja correlação em ambas as cultivares foi $r=0,99$, $\mathrm{p}<0,01$, o que possivelmente reflete maior taxa fotossintética e, consequentemente, maior acúmulo de biomassa da planta inteira. Haynes (1980) também relatou alta correlação entre a área foliar e a produção da massa de matéria seca em leguminosas.
Houve correlação positiva da massa de matéria seca da planta inteira produzida pelas mudas da 'B-10' e da 'Golden Star', respectivamente, com a altura $(r=0,99$ e $0,98, p<0,01)$; o diâmetro do caule $(\mathrm{r}=0,95$ e $0,98, \mathrm{p}<0,01)$; e a área foliar $(\mathrm{r}=0,99 \mathrm{e}$ $0,98, \mathrm{p}<0,01)$. Isso indica que essas características apresentaram comportamento diretamente proporcional ao acúmulo da massa de matéria seca da planta inteira das mudas de caramboleiras. Melo et al. (2005), estudando mudas de umbuzeiro, Franco et al. (2007) e Augostinho et al. (2008), com mudas de goiabeiras, encontraram resultados semelhantes para essas variáveis de crescimento.

De acordo com as considerações de Paiva e Oliveira (2006), a TCR assemelhou-se aos modelos descritos das curvas de crescimento da massa da matéria seca e do acúmulo de nutrientes. Após o início das avaliações, a máxima TCR obtida pela 'B10 ', para raízes, esteve compreendida no período de 283 - 308 DAT, e para o caule e as folhas, entre 208 - 233 DAT. Para 'Golden Star', o comportamento da máxima TCR para folhas assemelhou-se ao mesmo período da 'B-10'; entretanto, a máxima TCR desta cultivar, para caule e raízes, esteve entre $233-258$ DAT (Tabela 2).

Apesar das diferenças entre o período de maior TCR nos diferentes órgãos das mudas de caramboleiras, ambas tiveram, preferencialmente, a maior TCR nas folhas, o que sugere maior produção de biomassa das folhas, possivelmente para incrementar a área foliar e a taxa fotossintética.

A TCR sempre apresentou resultados positivos, indicando que, com o decorrer do experimento, houve incremento da massa de matéria seca nos órgãos estudados que, aliado ao pleno desenvolvimento vegetativo, justificam que as condições de cultivo, a solução empregada e a periodicidade de troca desta não limitaram o desenvolvimento das plantas.

TABELA 1- Resumo da análise de variância e resultados médios da altura, do diâmetro do caule, da área foliar e da massa da matéria seca das raízes, do caule, das folhas e da planta inteira, em caramboleiras cultivadas em solução nutritiva.

\begin{tabular}{|c|c|c|c|c|c|c|c|}
\hline \multirow{2}{*}{ Fatores } & \multirow[t]{2}{*}{ Altura } & \multirow{2}{*}{$\begin{array}{c}\text { Diâmetro } \\
\text { do caule }\end{array}$} & \multirow{2}{*}{$\begin{array}{l}\text { Área } \\
\text { foliar }\end{array}$} & \multicolumn{4}{|c|}{ Massa da matéria seca } \\
\hline & & & & Raízes & Caule & Folhas & Planta inteira \\
\hline Tempo cultivo $(\mathrm{T})$ & $76,60 * *$ & $11,76^{* *}$ & $54,00^{* *}$ & $77,25 * *$ & $237,21 * *$ & $360,47 * *$ & $421,37 * *$ \\
\hline Cultivares (C) & $2,84 \mathrm{~ns}$ & $1,53 \mathrm{~ns}$ & $1,74 \mathrm{~ns}$ & $43,91 * *$ & $0,03 \mathrm{~ns}$ & $0,05 \mathrm{~ns}$ & $1,44 \mathrm{~ns}$ \\
\hline Interação (C x T) & $\begin{array}{c}0,59 \mathrm{~ns} \\
\mathrm{~m}\end{array}$ & $\begin{array}{c}0,37 \mathrm{~ns} \\
\mathrm{~mm}\end{array}$ & $\begin{array}{c}0,61 \mathrm{~ns} \\
\mathrm{~cm}^{2}\end{array}$ & $20,65 * *$ & $6,47 * *$ & $\begin{array}{l}1,57 \mathrm{~ns} \\
\text { r planta }\end{array}$ & $5,40 * *$ \\
\hline 'B-10’' - & 0,86 & 9,04 & 2432,50 & 6,51 & 11,38 & 15,22 & 33,11 \\
\hline 'Golden Star' & 0,91 & 9,46 & 2615,67 & 8,09 & 11,28 & 15,10 & 34,47 \\
\hline CV $(\%)^{(1)}$ & 8,9 & 10,0 & 15,1 & 9,0 & 13,3 & 10,0 & 9,2 \\
\hline $\mathrm{CV}(\%)^{(2)}$ & 10,6 & 8,3 & 20,6 & 8,6 & 8,9 & 8,8 & 6,7 \\
\hline
\end{tabular}

${ }^{(1)} \mathrm{e}^{(2)}$ Coeficientes de variação para parcela e subparcela, respectivamente. ns e ** : não significativo e significativo $\mathrm{p}<0,01$, respectivamente. 
TABELA 2 - Taxa de crescimento relativo (TCR) dos órgãos das mudas de caramboleiras cultivadas em solução nutritiva.

\begin{tabular}{|c|c|c|c|c|c|c|c|c|}
\hline \multirow{3}{*}{$\begin{array}{l}\text { Período } \\
\text { dias }\end{array}$} & \multicolumn{4}{|c|}{ 'B-10' } & \multicolumn{4}{|c|}{ 'Golden Star' } \\
\hline & & & 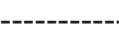 & - m & $g$ por $d$ & & & 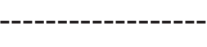 \\
\hline & Raízes & Caule & Folhas & Planta Inteira & Raízes & Caule & Folhas & Planta Inteira \\
\hline $208-233$ & 0,0039 & 0,0210 & 0,0570 & 0,0257 & 0,0048 & 0,0101 & 0,0283 & 0,0154 \\
\hline $233-258$ & 0,0027 & 0,0071 & 0,0104 & 0,0075 & 0,0268 & 0,0328 & 0,0179 & 0,0252 \\
\hline $258-283$ & 0,0033 & 0,0191 & 0,0249 & 0,0190 & 0,0049 & 0,0041 & 0,0210 & 0,0114 \\
\hline 283-308 & 0,0129 & 0,0134 & 0,0106 & 0,0119 & 0,0008 & 0,0143 & 0,0101 & 0,0095 \\
\hline
\end{tabular}

A

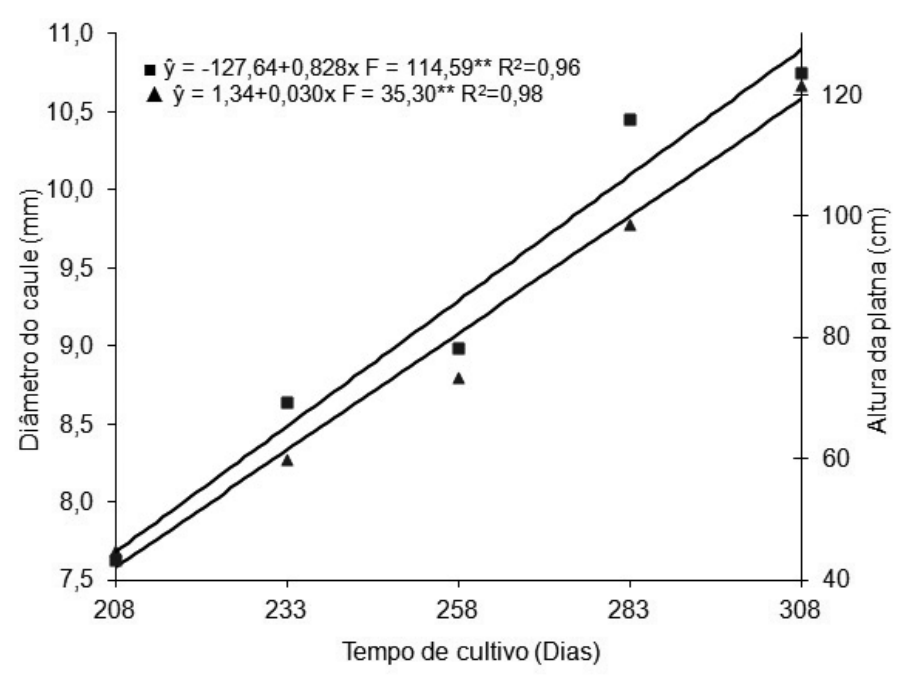

$\mathrm{B}$

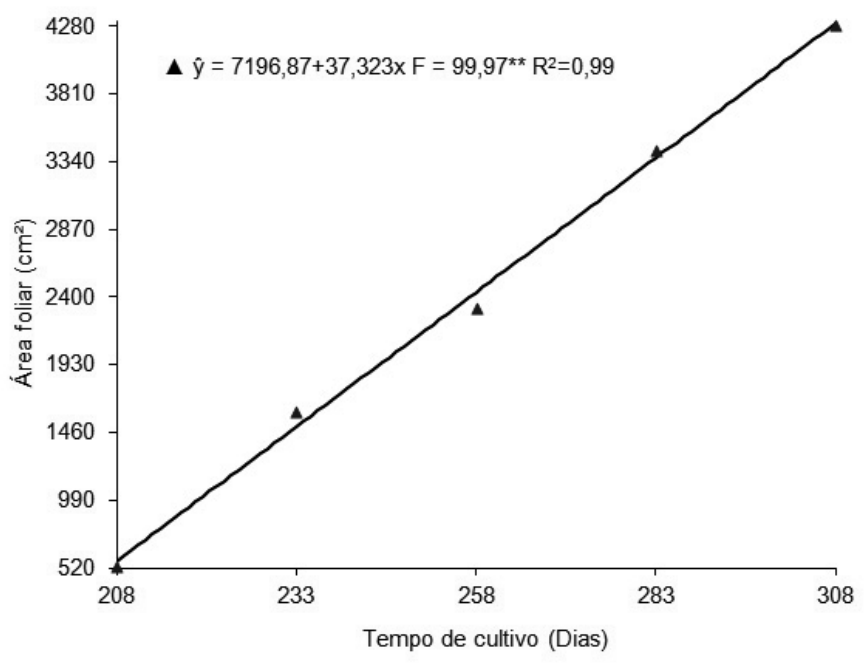


$\mathrm{C}$

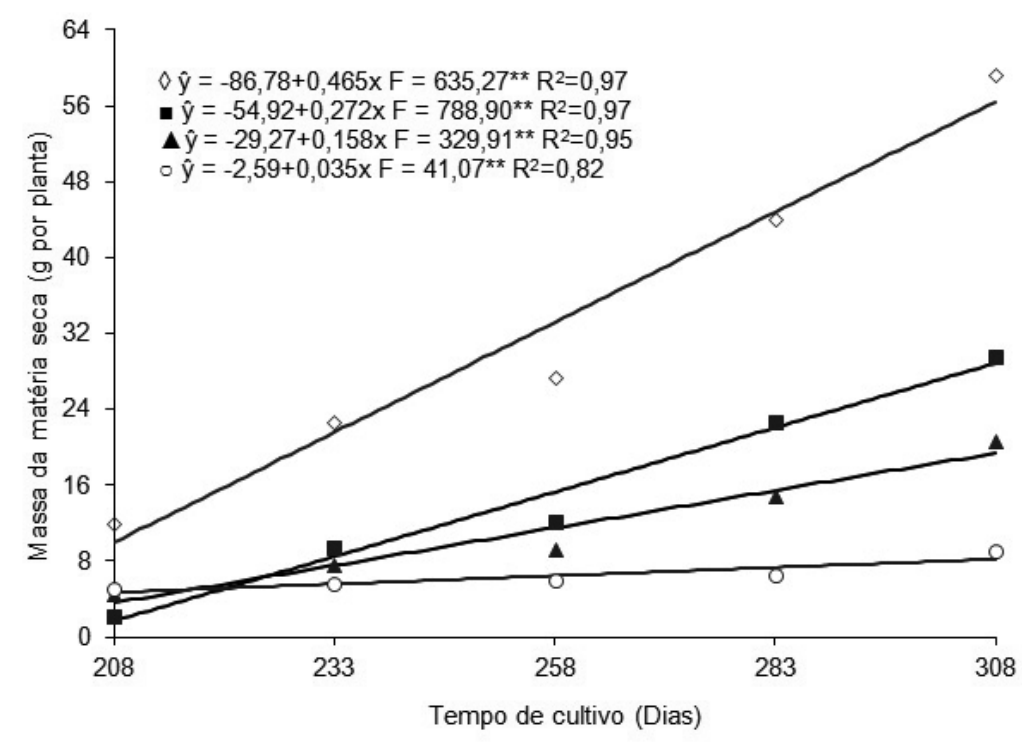

FIGURA 1 - Valor de F e coeficiente de determinação $\left(\mathrm{R}^{2}\right)$, obtidos nos estudos de regressão, sobre os efeitos do tempo de cultivo (dias) no diâmetro do caule $(\boldsymbol{\Lambda})$ e na altura (ם) (a), na área foliar $(\boldsymbol{\Delta})$ (b), e a massa da matéria seca da planta inteira $(\diamond)$, das folhas $(\boldsymbol{\square})$, do caule $(\boldsymbol{\Lambda})$ e das raízes (०) (c), em mudas de caramboleiras 'B-10', cultivadas em solução nutritiva. (**: p<0,01).

A

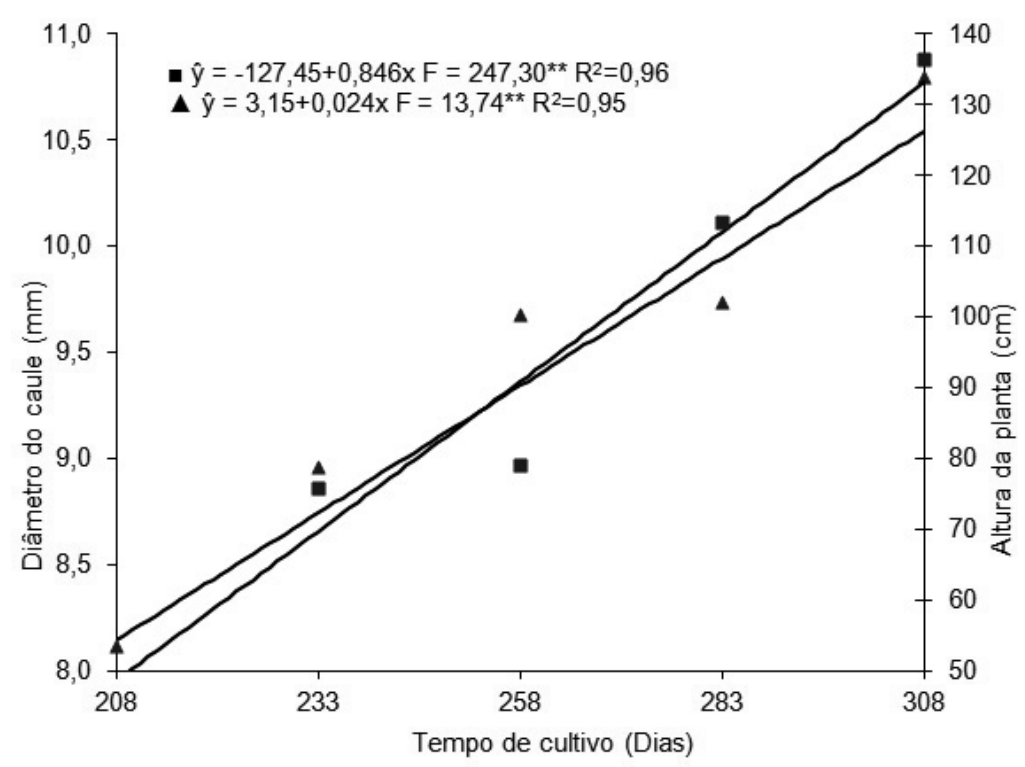




\section{CONTINUAÇÃO}

B

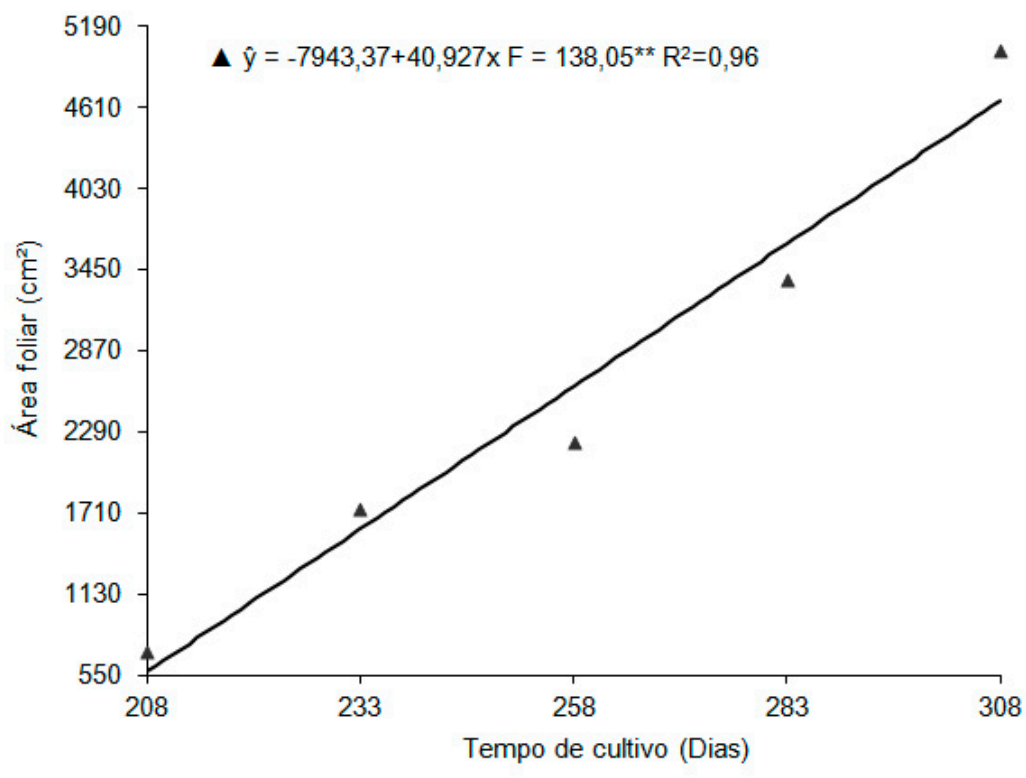

$\mathrm{C}$

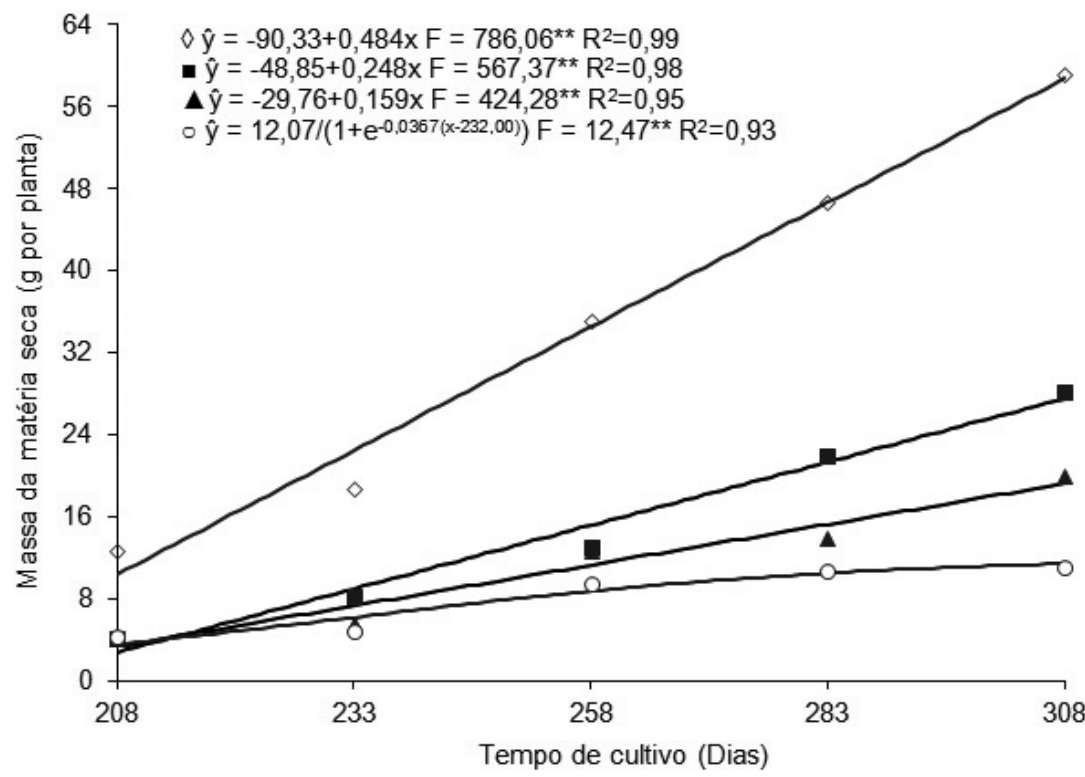

FIGURA 2 - Valor de F e coeficiente de determinação $\left(\mathrm{R}^{2}\right)$, obtidos nos estudos de regressão, sobre os efeitos do tempo de cultivo (dias) no diâmetro do caule ( $\boldsymbol{\Delta})$ e na altura $(\boldsymbol{\square})(\mathrm{a})$, na área foliar $(\boldsymbol{\Delta})(\mathrm{b})$, e a massa da matéria seca da planta inteira $(\diamond)$, das folhas $(\boldsymbol{\square})$, do caule $(\boldsymbol{\Delta})$ e das raízes $(\circ)$ (c), em mudas de caramboleiras 'Golden Star', cultivadas em solução nutritiva. (**: $p<0,01$ ). 


\section{CONCLUSÕES}

1-Não há diferenças no crescimento e, em geral, no acúmulo da massa de matéria seca entre as mudas das cultivares estudadas.

2-Há acúmulo linear da massa da matéria seca das mudas de caramboleira com o tempo de cultivo, sendo que o acúmulo médio é maior nas folhas $>$ caule $>$ raízes.

3-O período de maior acúmulo da massa de matéria seca e da TCR na planta inteira está compreendido entre $208-233$ e entre $233-258$ dias após o transplantio para a 'B-10' e a 'Golden Star', respectivamente.

\section{REFERÊNCIAS}

AUGOSTINHO, L. M. D.; PRADO, R. de M.; ROZANE, D. E.; FREITAS, N. Marcha de absorção de macro e micronutrientes em mudas de goiabeira 'Pedro Sato'. Bragantia, Campinas, v.67, n. 3, p.563-568, 2008.

BARBOSA, Z.; SOARES, I.; CRISÓTOMO, L. A. Crescimento de nutrientes por mudas de gravioleira. Revista Brasileira de Fruticultura, Jaboticabal, v.25, n.3, p.519-522, 2003.

BROWN, R. H. Growth of the green plant. In: TESAR, M. B. (Ed.). Physiological basis of crop growth and development. Madison: American Society of Agronomy. 1984. cap. 6, p. 153-174.

DONADIO, L. C.; SILVA, J. A. A.; ARAÚJO, P. S. R.; PRADO, R. M. Caramboleira (Averrhoa carambola L.). Jaboticabal: Sociedade Brasileira de Fruticultura, 2001. 81p.

ESTAT: sistema para análises estatísticas (v.2.0). Jaboticabal: Polo computacional, Departamento de Ciências Exatas, FCAV/UNESP, 1992.

FRANCO, C. F.; PRADO, R. de M.; BRAGHIROLLI, L. F.; ROZANE, D. E. Curva de crescimento e marcha de absorção de macronutrientes em mudas de goiabeira. Revista Brasileira de Ciência do Solo, Viçosa, MG, v.31, n.6, p.1429-1437, 2007.

FREITAS, N.; PRADO, R. de M.; ROZANE, D. E.; TORRES, M. H.; AROUCA, M. B. Marcha de absorção de nutrientes e crescimento de mudas de caramboleira enxertada com a cultivar Nota-10. Semina: Ciências Agrárias, Londrina, v. 32, n. 4, p. 1231-1242, 2011.
FURLANI, P. R.; SILVEIRA, L. C. P.; BOLONHEZI, D.; FAQUIN, V. Cultivo hidropônico de plantas. Campinas: Instituto Agronômico de Campinas, 1999. 52 p. (Boletim Técnico, 180).

GALAN-SAUCO, V. Carambola cultivation. Roma: FAO, 1993, 74p. (Plant Production and Protection Paper, 108).

GARDNER, F. P.; PEARCE, R. B.; MITCHELL, R. L. Physiology of crop plants. Ames: Iowa State University, 1985. 327p.

HAYNES, R. J. Competitive aspects of the grasslegume association. Advances in Agronomy, San Diego, v.33, p.227-261, 1980.

HOFFMAM, R.; VIEIRA, S. Análise de regressão. São Paulo: Ed. Huitec-Edusp, 1977. 339p.

MELO, A. S.; GOIS, M. P. P.; BRITO, M. E. B.; VIÉGAS, P. R. A.; ARAÚJO, F. P.; MÉLO, D. L. M. F.; MENDONÇA, M. C. Desenvolvimento de portaenxertos de umbuzeiro em resposta à adubação com nitrogênio e fósforo. Ciência Rural, Santa Maria, v.35, n.2, p.324-331, 2005.

OLIVEIRA, M. N. S. Comportamento fisiológico de plantas jovens de acerola, carambola, pitanga, cupuaçu, graviola, pupunha e biribá, em função da baixa disponibilidade de água no solo. 1996. 67f. Dissertação (Mestrado) - Escola Superior de Agricultura de Lavras, Lavras, 1996.

OLIVEIRA, M. N.; MAIA, G. A.; GUEDES, Z. B. L.; GUIMARÃES, A . C. L.; FIGUEIREDO, R. W. de. Características químicas e físico-químicas da carambola (Averrhoa carambola L). Ciência Agronômica, Fortaleza, v.20, n.2, p.129-133, 1989.

PAIVA, R.;OLIVEIRA, L. M. Fisiologia e produção vegetal. Lavras: Editora UFLA, 2006. 104p.

ROZANE, D. E.; PRADO, R. de M.; FRANCO, C. F.; NATALE, W. Eficiência de absorção, transporte e utilização de macronutrientes por porta-enxertos de caramboleira, cultivados em soluções nutritivas. Ciência e Agrotecnologia, Lavras, v.31, n.4, p.10201026, 2007.

SALISBURY, F. B.; ROSS, C. W. Plant physiology. $3^{\text {rd }}$ ed. Belmont: Wadsworth, 1985. 540p.

WELBANK, P. J. The effects of competition with Agropyron repens and of nitrogen and water supply on the nitrogen content of Impatiens parviflora. Annals of Botany, London, v.26, n.103, p.361-373, 1962. 